\title{
Pengaruh Komposisi Material Biokomposit dengan Matriks Polyester Berpenguat Serat Alam Terhadap Kekuatan Mekanik dan Fisik
}

\author{
Muh. Dede Pramono, Moh. Farid, Sigit Tri Wicaksono, \\ Jurusan Teknik Material \& Metalurgi, Fakultas Teknologi Industri, \\ Institut Teknologi Sepuluh Nopember (ITS) \\ Jl. Arief Rahman Hakim, Surabaya 60111 Indonesia \\ e-mail:mofaredo@gmail.com
}

\begin{abstract}
Abstrak-Penelitian ini dilakukan dengan tujuan untuk mengetahui pengaruh komposisi serat alam dalam komposit polymer terhadap kekuatan lentur dan densitas dari biokomposit dengan matriks polyester berpenguat serat rami, serat bambu betung, dan serat tebu. Dilakukan pengujian mekanik berupa pengujian kekuatan lentur dan melakukan perhitungan densitas sebagai pengujian fisik. Komposisi matriks dengan penguat seratnya diatur sebesar $\mathbf{7 0 \%}$ polyester dan $30 \%$ serat alam. Sebagai varibel yang digunakan pada penelitian ini adalah membuat dominasi komposisi jenis serat dalam bentuk jumlah berat yang yang terukur sehingga menghasilkan perbandingan jenis serat alam mana yang mempunyai nilai pengujian yang lebih baik. Dari hasil pengujian kekuatan lentur didapat bahwa biokomposit dengan dominasi serat tebu mempunyai nilai kuat lentur terbesar dengan $261,66 \mathrm{~kg} / \mathrm{cm}^{2}$ sedangkan biokomposit yang didominasi rami dan bambu secara berurutan menghasilkan kuat lentur sebesar $101,465 \mathrm{~kg} / \mathrm{cm}^{2}$ dan $185,89 \mathrm{~kg} / \mathrm{cm}^{2}$. Hasil perhitungan densitas menunjukkan densitas tertinggi dicapai oleh material biokomposit dengan dominasi komposisi serat rami $\mathbf{7 0 \%}$ Polyester : 20\% Serat Rami, 5\%Serat Bambu 5\%Serat Tebu) sebesar $1,049 \mathrm{~g} / \mathrm{cm}^{3}$.
\end{abstract}

Kata Kunci : polyester, serat rami,serat bambu,serat tebu, kekuatan lentur, densitas

\section{PENDAHULUAN}

B ANYAK sekali serat alami dari tumbuh - tumbuhan yang tidak termanfaatkan secara optimal demi menunjang kehidupan manusia. Serat terdiri dari ratusan bahkan ribuan filament, masing-masing filament memiliki diameter 5-15 um, sehingga dapat diproses lebih lanjut [1]. Khususnya Indonesia sebagai Negara tropis yang terletak tepat di garis khatulistiwa ditumbuhi berbagai macam tumbuhan yang dapat diolah menjadi serat yang mempunyai nilai tambah tinggi, bahakan seringkali bahan - bahan ini dibuang, dibakar, atau malah menjadi limbah yang mengganggu dan tak jarang dianggap sebagai hama bagi tumbuhan lain. Meskipun tidak dapat dipungkiri untuk mengelola menjadi produk mempunyai nilai guna tambahan dibutuhkan teknologi tinggi yang belum mampu dikuasai oleh bangsa Indonesia atau alat pengelolanya yang belum mampu di buat di dalam negeri sendiri. Bahan alami serat yang paling mudah ditemui disekitar kita adalah bamboo, rami, dan ampas tebu.

Menggunakan kemampuan dan fungsi ketiga bahan serat tersebut secara bersama - sama menjadi satu produk material dapat dikategorikan dan dikenal sebagai material komposit. Komposit pada umumnya terdiri dari dua unsur, yaitu serat sebagai pengisi (filler) dan bahan pengikat serat yang disebut matrik. Tipe material ini merupakan jenis yang paling banyak digunakan dan banyak dimanfaatkan sebagai aplikasi pengganti logam [2], bahan bangunan, komponen otomotif, penahan panas, penyerap suara, dan lain-lain..

Pemilihan bahan matriks diambil dari bahan yang mempunyai sifat ulet agar mampu meneruskan serta menahan tekanan dan tegangan geser yang diterima. Tapi untuk penelitian yang dilakukan ini dikembangkan komposit berserat dengan matrik yang relatif bersifat getas, maka digunakan polyester. Polyester sebagai matrik dapat membuat hubungan antara penyerapan energi statis yang semu dari berbagai serat dan penyerapan energi dinamisnya komposit. Hal ini menjadi alasan penggunaan komposit matriks polimer yang luas, karena harga murah, kekuatan tinggi, dan proses manufaktur yang relative sederhana [3].

Oleh Karena itu baru-baru ini banyak dikembangkan serat natural untuk mengatasi permasalahan tersebut. Serat natural bersifat lebih ramah lingkungan dan aman untuk kesehatan manusia.

Farid dan Heryanto [4] menunjukkan adanya kinerja penyerapan suara material komposit berbasis serat rami dalam penelitiannya. Selain itu Farid, dkk [5] mendapatkan kenaikan secara signifikan, untuk material polyester berpenguat serat rami untuk material polyester berpenguat serat bamboo.

Penggabungan serat bambu, rami, dan tebu sebagai reinforcement kemudian menggunakan polyester sebagai matriksnya diyakini merupakan terobosan dalam inovasi terciptanya material biokomposit yang mampu diaplikasikan untuk mempengaruhi hasil kekuatan mekanik dan fisik secara signifikan. Dengan terciptanya material ini diharapkan terjadinya revolusi terhadap lingkungan terutama dari penggunaan dalam bidang material sebelumnya yang kurang ramah lingkungan menjadi lebih mudah terurai, serta mampu mengurangi limbah, dan menurunkan harga produk - produk komposit dipasaran yang didominasi bahan sistetis suara lainnya yang tergolong mahal.

\section{METODE PENELITIAN}

\section{A. Material}

Bahan yang digunakan dalam penelitian ini adalah polyester sebagai matriks dan serat rami, serat bambu betung, serta serat tebu sebagai reinforcement. Serat rami 
didapatkan dari tanaman liar yang tumbuh bebas di alam, serat bambu betung yang dibeli dari pedagang yang mengambil pasokan $d i$ daerah Lumajang, serat ampas tebu didapatkan dari limbah rumah tangga dan PTPN Candi Sidoarjo, dan $\mathrm{NaOH}$ 5\%.

\section{B. Preparasi Bahan}

Pada serat alam yang digunakan ini dilakukan proses alkalisasi untuk menghilangkan komponen lignin dengan cara perendaman dalam $\mathrm{NaOH} 5 \%$ selama 24 jam. Setelah itu di keringkan dan dicacah hingga ukuran kecil. Hasil cacahan diblender hingga menjadi serbuk kasar yang kemudian diperhalus dengan cara digiling menggunakan mesin di tempat pengolahan serat dan kopi. Lalu di lakukan proses homeganasi ukuran dengan menggunakan mesin sieving yang ada di laboraturium Fisika Material hingga ukuran yang terpakai adalah 112$224 \mu$ mesh.

Polyester yang digunakan dibeli dari JUSTUS. Dengan perbandingan komposisi polyester dan katalis :

\section{Polyester : Katalis $\quad(95 \%: 5 \%)$}

\section{Pembuatan Spesimen}

Spesimen dibuat dengan menghitung massa polyester dan serat alam yang dibutuhkan. Fraksi massa matriks dan reinforcement yang digunakan adalah 70\%:30\%. Selanjutnya ditimbang massa polyester dan serat alam sesuai dengan volume cetakan pengujian yang akan digunakan. Metode yang digunakan untuk mencampurkan matriks dan reinforcement adalah metode hand lay-up [6].

Tabel 1

Variabel yang Digunakan

\begin{tabular}{ccccc}
\hline \hline \multirow{2}{*}{ Kode } & Matriks (\%) & \multicolumn{3}{c}{ Reinforcement (\%) } \\
Spesimen & Polyester & Rami & Bambu & Tebu \\
\hline I & $\mathbf{1 0 0}$ & - & - & - \\
II & $\mathbf{7 0}$ & 10 & 10 & 10 \\
III & $\mathbf{7 0}$ & 20 & $\mathbf{5}$ & 5 \\
IV & $\mathbf{7 0}$ & 5 & 20 & 5 \\
V & $\mathbf{7 0}$ & 5 & 5 & 20 \\
\hline \hline
\end{tabular}

\section{Pengujian Kuat Lentur}

Pengujian kekuatan lentur dilakukan di Balai Riset dan Standardisai (BARISTAND) Surabaya. Pada pengujian ini menggunakan metode 3 titik ( 3 Point) bending sesuai dengan standar ASTM D709 [7] dimana spesimen diletakan pada kedua tumpuan sebagai gaya penahan ke arah $\mathrm{Y}+$ dan diberikan beban dibagian tengah ke arah $\mathrm{Y}$-. Beban yang diberikan secara berlawan bertujuan untuk menghasilkan tegangan geser pada spesimen yang di uji. Pada pengujian dilakukan menggunakan dua spesimen untuk 1 variabel, agar setiap variable mempunyai data pembanding. Ukuran spesimen yang digunakan adalah $12,5 \times 1,27 \times 0,32 \mathrm{~cm}$.

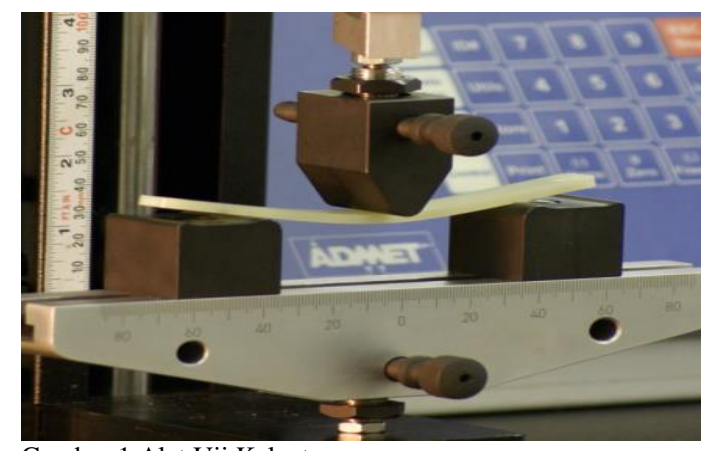

Gambar 1 Alat Uji Kelenturan

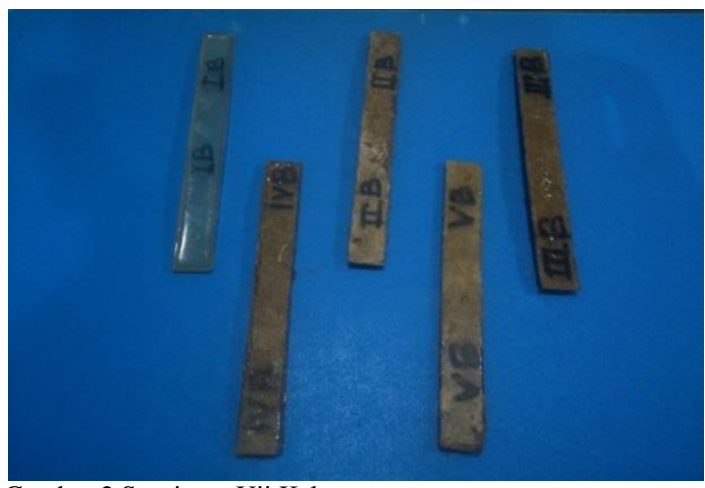

Gambar 2 Spesimen Uji Kelenturan

\section{E. Perhitungan Densitas}

Polyester merupakan material rigid yang mempunyai void, melakukan pengujian menggunakan rumus dan teori yang berdasarkan standard ASTM C271-99 [8]. Perhitungan densitas dilakukan dengan cara membagi massa dengan volume dari spesimen material biokomposit hasil pengujian absorbsi suara. Volume didapat dari pengukuran dimensi diameter, lebar dan tinggi spesimen absorbsi suara. Sedangkan massanya ditimbang dengan timbangan digital dengan estimasi error $\pm 0,05$.

\section{ANALISA DATA DAN PEMBAHASAN}

\section{A. Hasil Pengujian Lentur}

Dari hasil uji kekuatan lentur yang dilakukan pada keseluruhan sampel dimana setiap variable dibuat 2 sampel untuk pengujian, maka didapatkan kuat lentur masing-masing biokomposit material dengan komposisi sesuai rancangan awal dalam tabel berikut:

Tabel 2

Hasil Pengujian Kekuatan Lentur

\begin{tabular}{cccc}
\hline \hline \multicolumn{2}{c}{$\begin{array}{c}\text { Kode } \\
\text { Spesimen }\end{array}$} & $\begin{array}{c}\text { Hasil Uji Kuat Lenturr } \\
\left(\mathrm{Kg} / \mathrm{cm}^{2}\right)\end{array}$ & $\begin{array}{c}\text { Rata-rata Kuat Lentur } \\
\left(\mathrm{Kg} / \mathrm{cm}^{2}\right)\end{array}$ \\
\hline I & A & 724.5 & 990.82 \\
& B & 1257.14 & \\
II & A & 51.32 & 114.75 \\
& B & 178.18 & \\
III & A & 113.88 & 101.465 \\
& B & 89.05 & \\
IV & A & 201.36 & 185.89 \\
& B & 170.42 & 261.66 \\
V & A & 289.77 & \\
& B & 233.55 & \\
\hline \hline
\end{tabular}




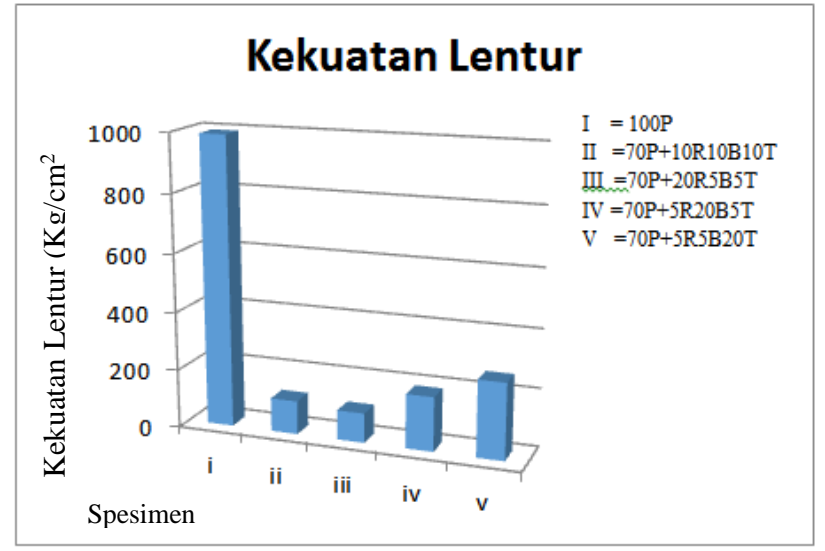

Gambar 3 Grafik Kekuatan Lentur

Gambar 3 menunjukkan bahwa kekuatan lentur tetinggi ada pada spesimen I dimana komposisinya adalah $100 \%$ polyester, mencapai $990,82 \mathrm{Kg} / \mathrm{cm} 2$. Namun karena komposisinya hanya polyester dan tidak dicampur material lain maka tidak bisa disebut kekuatan uji komposit. Spesimen I hanya dijadikan pembanding untuk polyester sebagai matriks dipadukan dengan serat alam sebagi reinforcement. Dari grafik dan tabel, kita bisa melihat bahwa material komposit yang mempunyai kekuatan lentur tertinggi ada pada spesimen $\mathrm{V}$ dimana kekuatan lenturnya mencapai 261,66 Kg/cm2 dengan komposisi $70 \%$ polyester dengan $5 \%$ serat rami, $5 \%$ serat bambu, dan $20 \%$ serat tebu. Sedangkan material II, III, dan IV masing - masing berurutan nilai kekuatan lenturnya berada pada angka $114,75 \mathrm{Kg} / \mathrm{cm} 2,101,465$ $\mathrm{Kg} / \mathrm{cm} 2$, dan $185,89 \mathrm{Kg} / \mathrm{cm} 2$.

Menurut Pankaj pandey dkk [9] faktor pembuatan spesimen komposit, dan distribusi serat ini bisa menyebabkan nilai kelenturan dari komposit dengan hand lay up menurun. Hal ini disebabkan karena ketika pada proses pembuatan material komposit menggunakan metode hand lay up manual, akan ada kecenderungan terjadi penjenuhan serat pada titik tertentu sehinggga menyebabnkan distribusi serat diseluruh luas permukaan tidak merata, selain itu hal ini bisa disebabkan adanya ketidakhomogenan dari komposit, sehingga menyebabkan kekuatan lentur yang berbeda dengan teori [10]. Jadi berdasarkan hasil pengujian, material komposit yang reinforcement nya didominasi oleh serat tebu memiliki kekuatan lentur yang paling baik jika akan diaplikasikan pada suatu model.

\section{B. Hasil Perhitungan Densitas}

Untuk mendapatkan angka untuk menghitung densitas berdasarkan formula dan standar ASTM yang digunakan, terlebih dahulu dilakukan pengukuran massa jenis dari tiap spesimen dengan cara menghitung volume dan massa nya. Lalu selanjutnya dilakukan perbandingan antara massa jenis pada teori dan massa jenis pada eksperiman. Dari percobaan didapatkan nilai massa jenis pada komposi serat rami, bambu dan serat ampas tebu dengan matriks polyester menggunakan fraksi massa masingmasing dengan komposisi (I) $100 \%$ polyester, (II) $70 \%$ polyester dengan $10 \%$ serat rami, $10 \%$ serat bambu, dan $10 \%$ serat tebu, , (III) $70 \%$ polyester dengan $20 \%$ serat rami, 5\% serat bambu, dan 5\% serat tebu, , (IV) $70 \%$ polyester dengan $5 \%$ serat rami, $20 \%$ serat bambu, dan
$5 \%$ serat tebu, , (V) $70 \%$ polyester dengan $5 \%$ serat rami, $5 \%$ serat bambu, dan $20 \%$ serat tebu, adalah sebagai berikut:

Tabel 3

Massa Jenis Bahan Berdasarkan Literatur

\begin{tabular}{cc}
\hline \hline Bahan & Massa Jenis g/cm3 \\
\hline Polyester & 1,1 \\
Rami & 1,5 \\
Bambu & 0,253 \\
Tebu & 0,237 \\
\hline \hline
\end{tabular}

Tabel 3 merupakan masa jenis dari bahan yang digunakan dalam pembuatan komposit saat belum dilakukan pencampuran, sehingga dilakukan pengukuran pada spesimen untuk dibandingkan perubahan densitas yang terjadi saat bahan belum dan sudah dibentuk menjadi komposit.

Tabel 4

Massa jenis spesimen setelah Matriks dan serat dicampurkan menjadi material komposit

\begin{tabular}{|c|c|c|c|c|c|}
\hline $\begin{array}{c}\text { Spesime } \\
\text { n } \\
\text { No }\end{array}$ & $\begin{array}{c}\text { Mass } \\
\text { a } \\
\text { gr }\end{array}$ & $\begin{array}{c}\text { Diamet } \\
\text { er } \\
\text { cm }\end{array}$ & $\begin{array}{c}\text { Teb } \\
\text { al } \\
\text { cm }\end{array}$ & $\begin{array}{c}\text { Volum } \\
\text { e } \\
\mathrm{Cm}^{3}\end{array}$ & $\begin{array}{c}\text { Massa } \\
\text { Jenis } \\
\text { g/cm3 }\end{array}$ \\
\hline I & 76,72 & 9,3 & 10 & $\begin{array}{c}74,318 \\
23\end{array}$ & $\begin{array}{c}1,0323 \\
17\end{array}$ \\
\hline II & 77,86 & 9,81 & 10 & $\begin{array}{c}75,545 \\
34\end{array}$ & $\begin{array}{c}1,0306 \\
39\end{array}$ \\
\hline III & 77,16 & 9,68 & 10 & $\begin{array}{c}73,556 \\
38\end{array}$ & $\begin{array}{c}1,0489 \\
91\end{array}$ \\
\hline IV & 69,51 & 9,82 & 10 & $\begin{array}{c}75,699 \\
43\end{array}$ & $\begin{array}{c}0,9182 \\
37\end{array}$ \\
\hline V & 69,36 & 9,76 & 10 & $\begin{array}{c}74,624 \\
06\end{array}$ & $\begin{array}{c}0,9294 \\
59\end{array}$ \\
\hline
\end{tabular}

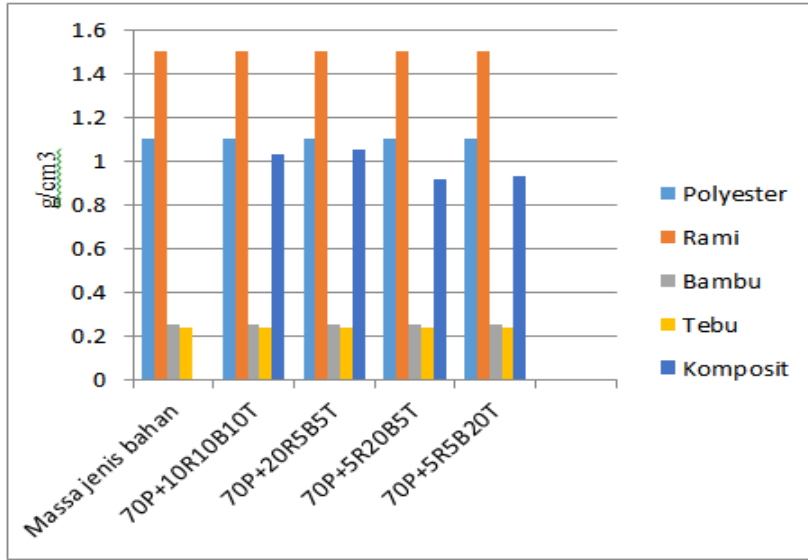

Gambar 4. Grafik Hasil Perhitungan Densitas

Dari hasil perhitungan dan pengukuran densitas komposit yang dilakukan, hampir terjadi terjadi peningkatan densitas pada semua material komposit jika dibandingkan dengan bahan yang densitasnya yang didapatkan dari hasil studi literatur. Penurunan hanya terjadi pada material komposit yang campuran seratnya didominasi oleh serat rami.

\section{KESIMPULAN}

1) Material biokomposit dengan kekuatan lentur tertinggi terdapat di komposisi dengan dominasi tebu, dengan kekuatan lentur mencapai 261,66 $\mathrm{Kg} / \mathrm{cm} 2$ mempunyai komposisi $70 \%$ polyester 
dengan 5\% serat rami, 5\% serat bambu, dan 20\% serat tebu.

2) Nilai densitas biokomposit tertinggi terdapat pada campuran dengan spesifikasi $70 \%$ polyester dengan $5 \%$ serat rami, $5 \%$ serat bambu, dan $20 \%$ serat tebu, dengan nilai mencapai $1,048991 \mathrm{~g} / \mathrm{cm}^{3}$

\section{UCAPAN TERIMAKASIH}

Para penulis mengucapkan terima kasih kepada Program Riset Unggulan Jurusan 2016 yang didanai oleh Jurusan Teknik Material dan Metalurgi FTI ITS.

\section{DAFTAR PUSTAKA}

[1] Gay, D.2015. Composite Materials : Design and Applications 3rd Edition. Boca Raton: CRC Press.

[2] A. Wirajaya. 2007. "Karakteristik Komposit Sandwich Serat Alami Sebagai Absorber Suara,” Tugas Akhir, ITB, Bandung, Indonesia.

[3] Kaw, Autar K. 2006. Mechanics of Composite Materials 2nd Edition. New York : Taylor and Francis, Inc.

[4] Farid, Moh, T.Heriyanto, 2013. Correlation of Normal Incidence Sound Absorption Coefficient (NAC) and Random Insidence Sound Absorption Coefficient (RAC) of Polyester/Ramie Fibre Composite Materials, Advance Material Research, Vol.789, pp.269-273

[5] Farid, Moh., H. Ardhyananta, V. M. Pratiwi, S. P Wulandari, 2015. Correlation between Frequency and Sound Absorption Coefficient of Polymer Reinforced Natural Fibre. Advanced Materials Research. Vol.1112, pp. 329-332.

[6] Sulistijono. 2012. Mekanika Material Komposit.Surabaya : itspress.

[7] ASTM D790 (2003), Standard test methods for flexural properties of unreinforced and reinforced plastics and electrical insulating materials, Annual book of ASTM Standards, Vol.08.01, American Society for Testing and Materials (ASTM), Philadelphia, USA.

[8] ASM Metal Handbook Vol. 21

[9] Pandey Pankaj., Bajwa Dilpreet., Ulven Chad., Bajwa Sreekala. Influence of Hybridizing Flax and Hemp-Agave Fibers with Glass Fiber as Reinforcement in a Polyurethane Composite. North Dakota State University : Published on 19 May 2016

[10]M. Agung, and M. Farid, "Pengaruh Variasi Komposisi Serat Terhadap Nilai Koefisien Absorpsi Suara dan Perilaku Mekanik Pada Komposit Serat Ampas Tebu Dan Bambu Betung Dengan Matriks Gypsum," Tugas Akhir, Jurusan Teknik Material dan Metalurgi, ITS, Surabaya (2015). 